\title{
Colloquium
}

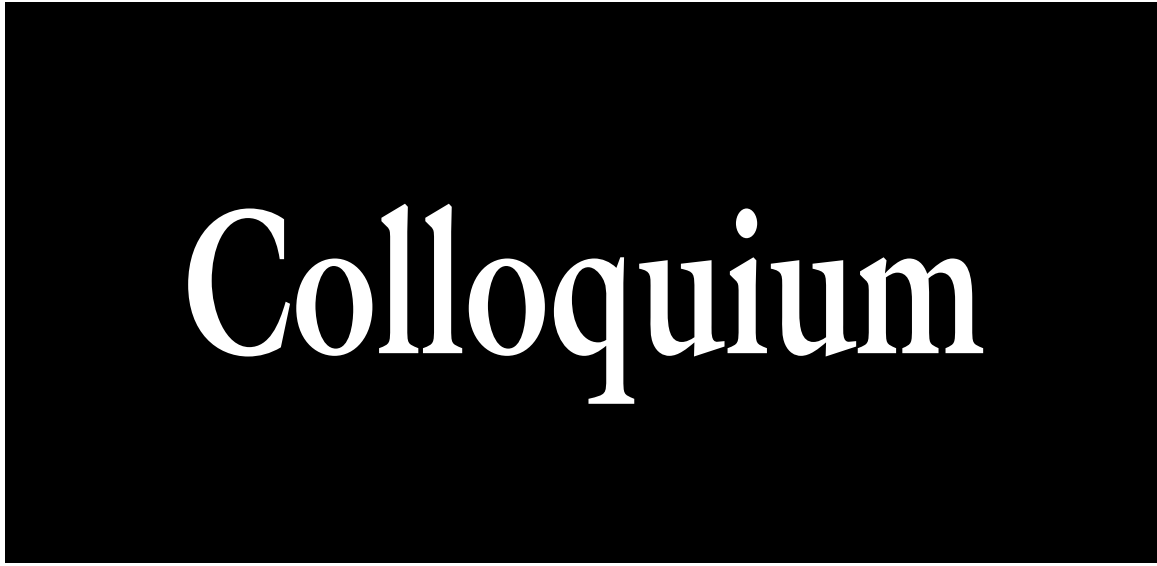

\section{How Agricultural Engineers Develop Mechanical Harvesters: The University Perspective}

\author{
Jesús A. Gil-Ribes ${ }^{1}$, Louise Ferguson ${ }^{2}$, Sergio Castro-Garcia ${ }^{1,3}$, \\ and Gregorio L. Blanco-Rodán ${ }^{1}$
}

ADDITIONAL INDEX wORDs. canopy shaker, mechanization, Olea europaea, olive, trunk shaker

SUMmaRY. Developing mechanical harvesting is the most effective, and most difficult, factor in improving horticultural crop profitability. It requires simultaneous incremental changes by multiple entities; engineers, horticulturists, food scientists, economists, local extension personnel, the commercial harvester industry, growers, and displaced laborers and their management. There is a narrow annual testing window. The initial research by engineers and horticulturists focuses on developing effective removal technologies and can be applied or basic. When funding is local, the research is generally applied and is usually an adaptation of existing technology. With national funding, the research is basic or investigates novel technologies. Both are conducted first on model systems or individual plants. Properly executed, both types can be published, but publication is difficult if engineering parameters are changed during the trials. Evaluation of developed removal technologies requires cross-disciplinary teams to evaluate the effects on the final marketable product quality and long-term plant health. Publications can be produced on testing technology or effects on marketable product quality or plant health. An industry education program with field days, industry publications and websites, and annual presentations should frequently report progress. Finally, a prototype should be demonstrated to show the economic feasibility of a mobile platform with catching technology. The research team then expands to include the harvester industry and grower cooperators. Orchard adaptations to increase harvester efficiency are incorporated at this point. Usually by this time all research is applied and the funding local. If results demonstrate economic feasibility, the technology should now segue to the commercial harvester industry as university laboratories mostly lack the capacity to generate truly commercial harvesters. Publications could be delayed to avoid premature disclosure to make patents achievable and to facilitate cooperation between university researchers and commercial fabricators.

$\mathrm{T}$ he strategy for developing mechanical harvesting of a crop comes from analyzing its technical, economic, social, and environmental aspects. However, the primary drivers are generally the unsustainable high hand harvest costs and lack of available labor, which threatens profitability and industrial survival. Specific objectives are to improve profitability and production technology, reduce worker occupational injury, and decrease reliance on an unreliable workforce, or a combination of the above. Succeeding requires a multidisciplinary team, simultaneously investigating different aspects of harvester development and efficiency, orchard management, and final product quality. Finally, financing from the local industry, national, or international organizations is needed. The cooperating researchers are engineers, horticulturists, food technologists, agricultural economists, producers, workers, and their representatives.

The academic engineer actively participates in both the development and education components of developing mechanical harvesting, particularly the final step, prototype development. From a university perspective, an agricultural engineer faces limitations in developing mechanical harvesting of a crop. Normally, national or international funding for research activities within a university is connected to scientific productivity, while private funding tends to be more closely linked to transferring knowledge, creating patents, and often is matched with public funding to promote an initiative. Also, continuing scientific publication may be delayed if patents are an objective. Generating data are difficult, particularly for tree crops, due to alternate bearing cycles and short harvest windows. Lastly, the difficulty in generating data is increased by the need to coordinate the research through the cooperation of farmers, manufacturers, and the university. Universities often do not have the capacity to fabricate harvesting machinery, and more often, the commercial orchards and the practical experience of harvesting to obtain a commercial comparison with hand harvesting. They definitely do not have a manufacturer's capacity to generate the final product. This article outlines, using olive (Olea europaea) as an example, the progression of research, extension education, and the funding required to conduct a mechanical harvesting development program from the point of view of a university and in collaboration with farmers, manufacturers, marketers, and their representatives.

\section{Developing mechanical harvesting of olive}

Olive growing is a symbol of agriculture, culture, and life in the Mediterranean. The olive grove is a defining element in the countryside, a factor in the conservation of soil, 
flora, and fauna and a major component of the Mediterranean diet and culture (Gómez-Limón et al., 2012). Olive is one of the most economically important crops in Spain, producing $9 \%$ of agricultural production and income. Olive groves occupy $15 \%$ of the arable land in Spain, 2.6 million hectares, producing $47 \%$ of the world's olive oil (Ministerio de Agricultura, Alimentación y Medio Ambiente, $2013)$. Over $74 \%$ are traditional dry land orchards planted at low tree densities (30-180 trees/ha) and have low yields ( 1.1 to $4.5 \mathrm{Mg} \cdot \mathrm{ha}^{-1}$ ). The trees have multiple trunks and wide canopies (Vossen, 2007). The orchards are typically small, hilly and difficult to access, and expensive to harvest by hand (Gil-Ribes et al., 2009). The first significant harvesting technology investigations were done from the $1940 \mathrm{~s}$ through the 1960s (Ferguson et al., 2010). Since then, there has been little innovation in harvesting olive than the development of the high-density olive oil groves developed for mechanical harvesting with adapted vineyard harvesters (Gil-Ribes et al., 2009).

There is no universal solution for the mechanical harvesting of the widely different types of olive groves (Rallo et al., 2013). The harvesting method depends primarily on tree training followed by orchard layout and size, cropping, slope of the land, and available workforce. The crop's low profit margins, until recently, precluded harvesting innovations. The solution is a simultaneous adaptation of the trees and the harvesting machinery for the existing and new groves (Ravetti and Robb, 2010).

Currently, manual harvesting with poles is the primary harvesting method in Spain. The harvest efficiency is close to $95 \%$, but its productivity at $15-25 \mathrm{~kg} \cdot \mathrm{h}^{-1}$ per worker

\footnotetext{
This paper was part of the colloquium "Strategy for Developing Mechanical Harvesting of Horticultural Crops: Simultaneous Short-, Medium-, and Longterm Strategies" held 24 July 2013 at the ASHS Annual Conference, Palm Desert, California, and sponsored by the Production and Harvest Mechanization $(\mathrm{MECH})$ Working Group.

The authors wish to acknowledge the support of Spanish Ministry of Economy and Competitiveness (Pre-commercial public procurement Mecaolivar).

${ }^{1}$ Department of Rural Engineering, Escuela Tecnica Superior de Ingenieria Agronomica y de Montes, University of Cordoba, Cordoba, Spain

${ }^{2}$ Department of Plant Sciences, University of California, Davis, CA 95616

${ }^{3}$ Corresponding author. E-mail: scastro@uco.es.
}

is low and expensive, averaging more than $€ 0.2 / \mathrm{kg}$ (Rallo et al., 2013). Incorporating hand-held machines improves productivity to $30-50 \mathrm{~kg} \cdot \mathrm{h}^{-1}$ per worker and reduces the cost to $€ 0.18 / \mathrm{kg}$ to $€ 0.24 / \mathrm{kg}$ according to tree fruit production. However, the efficiency is highly dependent upon operator skill and cannot be considered a technique for mechanical harvesting as it does not eliminate the reliance on labor availability (Ferguson, 2006).

Currently, mechanical harvesting technologies used in multiple other tree and bush crops clamp or contact the trunk or canopy to apply direct vibration energy. These technologies have been adapted and developed for both table and oil olive groves. The process discussed here highlights the importance of the research done through public funding, regionally and nationally, and private funding by the farmer and commodity organizations and their representatives.

\section{Short-term strategies}

In the short term, developing mechanical harvesting is focused on adapting and improving the existing technology and harvesters; typically solving a specific engineering problem. The advantages of this approach are the reduced time required, 1 to 3 years, well-defined objectives, the ability to make progress for the associated industry, and opportunity for extension education and applied scientific publication. The funding support is generally from the commodity organizations, though national funding is possible. The creation of a prototype is not usually necessary. A good example is the adaptation of the trunk shakers used in bush and vine crops for table and oil olives (Ferguson, 2006).

Trunk shakers, harvesters that clamp the trunk and shake the tree, are among the most widely used technologies for mechanical harvesting (Di Vaio et al., 2012; Farinelli et al., 2012). Adapting trunk shakers to a new tree crop includes evaluating the tree architecture, canopy density, pruning, injury susceptibility, orchard density, and bearing habit. Also, factors as fruit weight, size and detachment force, and fruit displacement required, how to produce the required force in the tree, the appropriate trunk location to place to clamp, the force the clamp should apply, and the interaction of all these factors play a main role in harvesting process (Ferguson et al., 2010). Determining the modal parameters of the olive trees allowed us to characterize its dynamic response to forced vibration (CastroGarcia et al., 2008). With these results, the most suitable frequency ranges were established for shaking olive trees. The problems of local resonance and the ways in which the tree dissipated the energy transmitted to remove the fruit were both identified. Studying the machinery enabled detection and correction of problems with resonance and transmission of vibration in the harvester heads (Castro-Garcia et al., 2007). Improving the harvester heads reduced the trunk damage and extended harvester life (Affeldt et al., 1988). Direct measurement of the tree vibration process while adjusting the force applied was necessary to evaluate the tree and machine together, and for determining energy efficiency. Analyzing the process of the detachment and the fruit harvesting enabled us to make specific recommendations for harvester operation, shaking time (Blanco-Roldán et al., 2009), and vibration frequency (Sessiz and Özcan, 2006). All harvesting methods must produce a marketable product. Production of high quality virgin olive oil requires harvesting at the appropriate time, and reducing fruit damage and postharvest storage time before processing (Clodoveo et al., 2014). Harvest efficiency is the more important factor in developing harvesting machinery for olive oil production, while fruit quality plays a main role during table olive harvesting (Ferguson et al., 2010). Lastly, it is important to assess postharvest fruit handling as this identifies the factors that reduce fruit quality during mechanical harvesting (JiménezJiménez et al., 2013).

\begin{tabular}{llll}
\hline $\begin{array}{l}\text { Units } \\
\begin{array}{l}\text { To convert U.S. to SI, } \\
\text { multiply by }\end{array}\end{array}$ & U.S. unit & SI unit & $\begin{array}{l}\text { To convert SI to U.S., } \\
\text { multiply by }\end{array}$ \\
\hline 0.4047 & $\mathrm{acre}(\mathrm{s})$ & $\mathrm{Ha}$ & 2.4711 \\
0.4536 & $\mathrm{lb}$ & $\mathrm{Kg}$ & 2.2046 \\
2.2417 & ton $(\mathrm{s}) / \mathrm{acre}$ & $\mathrm{Mg} \cdot \mathrm{ha}^{-1}$ & 0.4461
\end{tabular}


Canopy contact systems, harvesters that apply a force vibration by rods directly into the bearing branches, were first developed for grape (Vitis vinifera), coffee (Coffea arabica), and citrus (Citrus sp.) (Ferguson et al., 2010). These harvesters are now being adapted for the traditional widely spaced olive orchards (Fig. 1) (SolaGuirado et al., 2014). Adapting olive trees for canopy contact harvesters required knowing the olive canopy's parameters, the tree's impedance to shaking (Savary et al., 2010), the olive fruit's detachment force and trajectory, and the effect of all these factors on harvested fruit quality (CastroGarcia et al., 2009). The prototype shown in Fig. I was further improved with the addition of a catch frame, as shown in Fig. 2. This second phase prototype harvester still has limitations of weight, size, and mobility. Continued development into a marketable harvester will require funding from manufacturers. Some countries, including Spain into the European Union, have a public/private approach designed to collaboratively create just such prototypes: "pre-commercial procurement" [PCP (European Commission, 2008)]. A PCP agreement allows

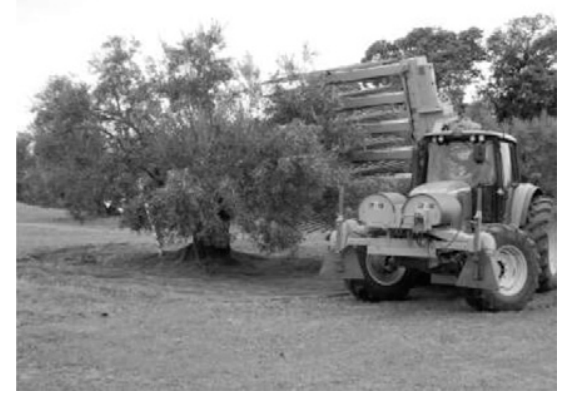

Fig. 1. Canopy shaker (Oxbo 3210; Oxbo International, Byron, NY) harvesting a traditional olive tree.

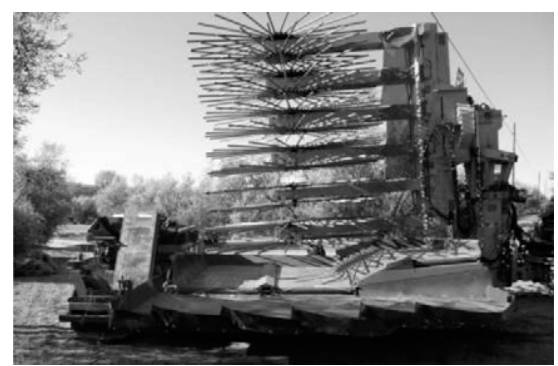

Fig. 2. Canopy shaker (Oxbo 3210; Oxbo International, Byron, NY) with a catch frame prototype adapted to harvest traditional olive trees. simultaneous development of multiple ideas, in which the public purchaser does not reserve the research results for its own use. Both, private and public participants, assume the risks and benefits of research results to develop an innovative solution that outperforms other available options.

\section{Medium-term strategies}

Among the more common medium-term strategies for developing mechanical harvesting are adapting existing orchards and developing new orchards. The overall objective with both strategies is to increase final harvester efficiency, the percentage of fruit removed from a given tree and captured in the harvest frame, and harvest speed, the number of trees harvested per hour of operation, while maintaining fruit quality. In existing orchards, pruning, mechanical, hand, or a combination of both, can make the fruit more accessible, detachable, or captured in a catch frame (Peterson, 2005 ). Developing new, more tightly spaced hedgerow orchards can achieve the same result with the added benefit of higher early yields due to higher tree density (Rallo et al., 2013). Also, innovations in horticultural manipulations, trellising, fruit abscission agents, and mechanical pruning, can enhance harvester efficiency (Burns et al., 2005; Lavee, 2010). This research also requires a multidisciplinary team and longer term funding. At least 4 to 6 years is required to adapt existing orchards as the effects of the different pruning practices on fruit yield and quality must also be demonstrated (Dias et al., 2012). At least 10 years is required to develop new orchards. It is particularly important to incorporate an economic analysis from orchard establishment through production maturity.

Mechanical harvesting is adapted primarily because hand labor is too expensive or unavailable. Demonstrating that net return is maintained or improved with mechanical harvesting is necessary. Usually, the funding sources are commodity organizations and national, and rarely, intergovernmental organizations. Commercial harvester fabricators may join the research effort once the above studies are in progress or completed and provide continuing funding. At this time, new technologies are introduced and prototypes developed at the request of growers or marketers in collaboration with manufacturers. These developments generally generate applied research data for publication. However, the desire for patents by either the academic engineers or commercial fabricators shall be according to research agreement. Along with the research and development program, field demonstrations and annual presentations of the results are particularly important. As growers are exposed to the harvesters and adapted orchards, they begin to adapt to the concept and provide helpful feedback.

\section{Long-term strategies}

Long-term strategies for developing mechanical harvesting include major changes in the crop and introducing new harvesting technologies. From a tree perspective, improvement would include breeding or selecting trees with any factor that makes them easier to harvest (Ferrante et al., 2004). Examples would be shorter trees with less dense canopies, fruit borne in a more easily harvestable position, fruit with lower detachment forces, or a flesh that was not susceptible to bruising (Peterson, 2005). Tree improvement could also include grafting existing cultivars on rootstocks that produce the above changes in the scions. Breeding is how most major improvements in tree crops have been produced to date. However, tree improvement through traditional or molecular breeding is very long-term, requiring at least 20 years.

The introduction of new novel mechanical harvesting technologies is the second long-term strategy. Currently, these technologies are not only speculative, but possibilities clearly include harvesters that fly, harvesters consisting of separate but coordinated harvesting heads and catch frames, unmanned or remote control harvesters, and robotics. Sensors might control on the spot adaptations to individual tree parameters including crop load, position, maturity, and fruit temperature and moisture content.

These two long-term strategies have one constant in common with both short- and medium-term strategies: improvements in mechanical harvesting technology and tree type must progress in tandem. No successful development of mechanical harvesting of tree crops has been developed with either strategy alone (Peterson, 2005). 


\section{Conclusions}

Developing mechanical harvesting for horticultural crops is always difficult. It requires a coordinated multidisciplinary team, continuous close collaboration and an educational extension program, field days, websites, reference materials, test field, and feedback from farmers, laborers, marketers, equipment fabricators and funding bodies. Medium- and long-term strategies must be carried out simultaneously as profitability of the industry must be maintained in traditional orchards while simultaneously developing newer more potentially profitable orchards. Finally, mechanical harvesting research is difficult for academic agricultural engineers early in their careers as scientific productivity could be negatively affected; it is difficult to produce publishable data while responding to the changes required during field experimentation. Patents can compensate for publication but require significant time and investment to obtain (Dietz and Bozeman, 2005). However, if successful, the development of mechanical harvesting generates new engineering and horticultural knowledge as well as increased production horticulture and profitability of the target commodities as well as that of the harvester fabricators.

\section{Literature cited}

Affeldt, H., G. Brown, J. Gerrish, and T. Esch. 1988. Elimination of adverse dynamic shaker loading on fruit and nut trees. Trans. Amer. Soc. Agr. Eng. 31: 1649-1655.

Blanco-Roldán, G.L., J.A. Gil-Ribes, K. Kouraba, and S. Castro-Garcia. 2009. Effects of trunk shaker duration and repetitions on removal efficiency for the harvesting of oil olives. Appl. Eng. Agr. 25:329-334

Burns, J., R. Buker, and F. Roka. 2005. Mechanical harvesting capacity in sweet orange is increased with an abscission agent. HortTechnology 15:758-765.

Castro-Garcia, S., G.L. Blanco-Roldán, J.A. Gil-Ribes, and J. Aguera-Vega. 2008. Dynamic analysis of olive trees in intensive orchards under forced vibration. Trees (Berl.) 22:795-802.
Castro-Garcia, S., J.A. Gil Ribes, G.L. Blanco Roldán, and J. Aguera-Vega. 2007. Mode shapes evaluation of trunk shakers used in oil olive harvesting. Trans. Amer. Soc. Agr. Biol. Eng. 50:727-732.

Castro-Garcia, S., U.A. Rosa, C.J. Gliever, D. Smith, J.K. Burns, W.H. Krueger, L. Ferguson, and K. Glozer. 2009. Video evaluation of table olive damage during harvest with a canopy shaker. HortTechnology 19:260-266.

Clodoveo, M.L., R.H. Hbaieb, F. Kotti, G.S. Mugnozza, and M. Gargouri. 2014. Mechanical strategies to increase nutritional and sensory quality of virgin olive oil by modulating the endogenous enzyme activities. Comprehensive Rev. Food Sci. Food Safety 13:135-154.

Di Vaio, C., N. Marallo, S. Nocerino, and F. Famiani. 2012. Mechanical harvesting of oil olives by trunk shaker with a reverse umbrella interceptor. Adv. Hort. Sci. 26:176-179.

Dias, A., J. Peca, and A. Pinheiro. 2012. Long-term evaluation of the influence of mechanical pruning on olive growing. Agron. J. 104:22-25.

Dietz, J.S. and B. Bozeman. 2005. Academic careers, patents, and productivity: Industry experience as scientific and technical human capital. Res. Policy 34:349-367.

European Commission. 2008. Precommercial procurement: Driving innovation to ensure high quality public services in Europe. Office Offic. Publ. European Communities, Luxembourg, Luxembourg.

Farinelli, D., S. Tombesi, F. Famiani, and A. Tombesi. 2012. The fruit detachment force/fruit weight ratio can be used to predict the harvesting yield and the efficiency of trunk shakers on mechanically harvested olives. Acta Hort. 965:61-64.

Ferguson, L. 2006. Trends in olive harvesting. Grasas Aceites 57(1):9-15.

Ferguson, L., U.A. Rosa, S. Castro-Garcia, S.M. Lee, J.X. Guinard, J. Burns, W.H. Krueger, L. Ferguson, and K. Glozer. 2010. Mechanical harvesting of California table and oil olives. Adv. Hort. Sci. 24:5363.

Ferrante, A., D.A. Hunter, and M.S. Reid. 2004. Towards a molecular strategy for improving harvesting of olives (Olea europaea L.). Postharvest Biol. Technol. 31:111-117.

Gil-Ribes, J.A., G.L. Blanco-Roldán, and S. Castro-Garcia. 2009. Mecanización del cultivo y de la recolección en el olivar. Junta de Andalucia, Seville, Spain.

Gómez-Limón, J.A., A.J. Picazo-Tadeo, and E. Reig-Martínez. 2012. Eco-efficiency assessment of olive farms in Andalusia. Land Use Policy 29:395-406.

Jiménez-Jiménez, F., S. Castro-Garcia, G.L. Blanco-Roldán, E.J. Gonzalez-Sanchez, and J.A. Gil-Ribes. 2013. Isolation of table olive damage causes and bruise time evolution during fruit detachment with trunk shaker. Span. J. Agr. Res. 11:65-71.

Lavee, S. 2010. Integrated mechanical, chemical and horticultural methodologies for harvesting of oil olives and the potential interaction with different growing systems. A general review. Adv. Hort. Sci. 24:5-15

Ministerio de Agricultura, Alimentación y Medio Ambiente. 2013. Encuesta de superficies y rendimientos, Spain. 22 May 2013. <http://www.magrama.gob. es/es/estadistica/temas/novedades/ Olivar2012_tcm7-262578.pdf>.

Peterson, D.L. 2005. Harvest mechanization progress and prospects for fresh marker quality deciduous tree fruits. HortTechnology 15:72-75.

Rallo, L., D. Barranco, S. Castro-Garcia, D.J. Connor, M. Gómez del Campo, and P. Rallo. 2013. High-density olive plantations. Hort. Rev. 41:303-384.

Ravetti, L. and S. Robb. 2010. Continuous mechanical harvesting in modern Australian olive systems. Adv. Hort. Sci. 24:71-77.

Savary, S.K.J.U., R. Ehsani, J.K. Schueller, and B.P. Rajaraman. 2010. Simulation study of citrus tree canopy motion during harvesting using a canopy shaker. Trans. Amer. Soc. Agr. Biol. Eng. 53:1373-1381.

Sessiz, A. and M.T. Özcan. 2006. Olive removal with pneumatic branch shaker and abscission chemical. J. Food Eng. 76:148-153.

Sola-Guirado, R.R., S. Castro-Garcia, G.L. Blanco-Roldán, F. Jiménez-Jiménez, F.J. Castillo-Ruiz, and J.A. Gil-Ribes. 2014. Traditional olive tree response to oil olive harvesting technologies. Biosystems Eng. 118:186-193.

Vossen, P. 2007. Olive oil: History, production, and characteristics of the world's classic oils. HortScience 42:1093-1100. 